\title{
Intensive Robot-Assisted Gait Training in Individuals with Chronic Spinal Cord Injury: Case Series from Saudi Arabia
}

\author{
Naif Alraddadi \\ King Fahad Medical City, nalraddadi@gmail.com \\ Sanaa Madi \\ Senses Rehabilitation Clinic, sanamadi@hotmail.com
}

Follow this and additional works at: https://nsuworks.nova.edu/ijahsp

Part of the Physical Therapy Commons

\section{Recommended Citation}

Alraddadi N, Madi S. Intensive Robot-Assisted Gait Training in Individuals with Chronic Spinal Cord Injury: Case Series from Saudi Arabia. The Internet Journal of Allied Health Sciences and Practice. 2021 Oct 01;19(4), Article 4.

This Manuscript is brought to you for free and open access by the College of Health Care Sciences at NSUWorks. It has been accepted for inclusion in Internet Journal of Allied Health Sciences and Practice by an authorized editor of NSUWorks. For more information, please contact nsuworks@nova.edu. 


\title{
Intensive Robot-Assisted Gait Training in Individuals with Chronic Spinal Cord Injury: Case Series from Saudi Arabia
}

\begin{abstract}
Purpose: The aim of this study was to report whether intensive body weight-supported treadmill training with a robotic exoskeleton could improve over-ground functional mobility in individuals with chronic spinal cord injury and to investigate its feasibility and safety. Methods: This was a case series design. Two male individuals with chronic (> 1 year since injury) spinal cord injury (SCl) were included in this study. All subjects underwent intensive gait training sessions 5 times per week using exoskeleton for 12 weeks with a total of 60 sessions. The duration of the session was 60 minutes, including the installment of the HAL, gait training, and the removal of the HAL. The training was performed on a treadmill with adjustable speed and a lifter, under the supervision of a physiotherapist. Two types of outcomes were collected: treadmillassociated data and functional outcomes. Results: We observed a continuous increase in treadmill walking distance, time, and speed for both cases from baseline assessment until the end of the study at 12 weeks The findings from this study provide evidence that the Hybrid Assistive Limb (HAL) can be used with chronic spinal cord injury and can improve walking abilities in terms of distance, speed, and time. Conclusion: HAL can be used for gait training in rehabilitation facilities for individuals with chronic spinal cord injury and did not cause any serious adverse effects to the participating subjects. Our results support the findings of previous studies that show that treatment with HAL may result in improvement in gait parameters. However, more studies with a larger sample size are needed to compare the effect of HAL with conventional physical therapy
\end{abstract}

\section{Author Bio(s)}

Naif Alraddadi, PT, MSc, is the Director of the Spinal Cord Injury Rehabilitation Program and senior physical therapist at King Fahad Medical City, Riyadh, Saudi Arabia

Sanaa Madi, PT, PhD, is the head of the Rehabilitation Department and a senior pediatric physical therapist at Senses Rehabilitation Clinic, Riyadh, Saudi Arabia

\section{Acknowledgements}

The authors would like to extend their appreciation to $\mathrm{MOH}-$ Innovation Center-Riyadh and Abdul Latif Jameel Hospital- Jeddah, Saudi Arabia for their support. 


\title{
IITAHSP \\ The Internet Joumnal of Allied Health Sciences and Practice \\ Dedicated to allied health professional practice and education \\ Vol. 19 No. 4 ISSN 1540-580X
}

\section{Intensive Robot-Assisted Gait Training in Individuals with Chronic Spinal Cord Injury: Case Series from Saudi Arabia}

\author{
Naif Alraddadi ${ }^{1}$ \\ Sanaa Madi2
}

1. King Fahad Medical City

2. Senses Rehabilitation Clinic

Saudi Arabia

\begin{abstract}
Purpose: The aim of this study was to report whether intensive body weight-supported treadmill training with a robotic exoskeleton could improve over-ground functional mobility in individuals with chronic spinal cord injury and to investigate its feasibility and safety. Methods: This was a case series design. Two male individuals with chronic ( $>1$ year since injury) spinal cord injury (SCl) were included in this study. All subjects underwent intensive gait training sessions 5 times per week using exoskeleton for 12 weeks with a total of 60 sessions. The duration of the session was 60 minutes, including the installment of the HAL, gait training, and the removal of the HAL. The training was performed on a treadmill with adjustable speed and a lifter, under the supervision of a physiotherapist. Two types of outcomes were collected: treadmill-associated data and functional outcomes. Results: We observed a continuous increase in treadmill walking distance, time, and speed for both cases from baseline assessment until the end of the study at 12 weeks The findings from this study provide evidence that the Hybrid Assistive Limb (HAL) can be used with chronic spinal cord injury and can improve walking abilities in terms of distance, speed, and time. Conclusion: HAL can be used for gait training in rehabilitation facilities for individuals with chronic spinal cord injury and did not cause any serious adverse effects to the participating subjects. Our results support the findings of previous studies that show that treatment with HAL may result in improvement in gait parameters. However, more studies with a larger sample size are needed to compare the effect of HAL with conventional physical therapy.
\end{abstract}

Keywords: chronic spinal cord injury, hybrid assistive limb, exoskeleton, gait training, rehabilitation 


\section{INTRODUCTION}

An injury to the spinal cord is associated with many complications. The most common physiological consequences of a spinal cord injury $(\mathrm{SCl})$ are muscle paralysis or weakness and dysfunction of sensory and autonomic nervous systems below the level of injury. 1,2 This may result in difficulties or inability to perform activities of daily living (ADL), such as eating, bathing, use of a wheelchair, walking, etc. The extent of the impairments depends on the level and severity of the injury. ${ }^{3}$ Half of the spinal cord injuries are classified as incomplete injuries, meaning that there are preserved sensory and/or motor functions below the level of the lesion. 4,5 Individuals with incomplete $\mathrm{SCl}$ retains the ability to ambulate over-ground (with or without an assistive device). ${ }^{5}$ On the other hand, recovery of over-ground ambulation is not possible in individuals with complete $\mathrm{SCl} .{ }^{6}$ Restoration of walking and standing has high priority over other functions for individuals with $\mathrm{SCl}^{7}$

Many strategies have been utilized to improve gait in individuals with $\mathrm{SCl}$. Some of these strategies focus on the compensation of the lost function like long leg braces. Unfortunately, it has been documented that even with long leg braces, walking was not functional and required a high level of energy. ${ }^{8}$ Functional ambulation is defined as "the ability to walk, with or without the aid of appropriate assistive devices (such as prostheses, orthoses, canes or walkers), safely and sufficiently to carry out mobility-related activities of daily living."

On the other hand, there are strategies that are based on the concepts of neural control and motor plasticity. It is believed that repetitive and intensive gait training provides task-specific sensory inputs that may enhance walking abilities. ${ }^{10}$ Bodyweight supported treadmill (BWST) training is one of the most common techniques used in gait training after $\mathrm{SCl}$ as it is not limited by the individuals' level of injury. ${ }^{1}$ During BWST training, part of the individual's weight is supported by an overhead harness while legs are moved by therapists over the treadmill belt. This training allows for early initiation of gait training, weight-bearing activities, and coordinated stepping movements. ${ }^{11,12}$ Recent development in the field of gait rehabilitation resulted in the development of robotic exoskeletons that help reduce the load on the therapists. They are worn over the lower extremities and can be used over a treadmill or over-ground. ${ }^{13}$ Gait training with robotic exoskeletons requires less assistance, provides training for a longer duration, and allows for more physiologic and reproducible gait patterns than manual body-weight-supported gait training. ${ }^{12,14}$

Several studies have described the impact of gait training with Hybrid Assistive Limb (HAL). Studied population included stroke, spinal cord injury, cerebral palsy, and total knee arthroplasty. ${ }^{12,15-34}$ Improvements in functional mobility, overground walking, muscle strength, and motor functions of patients with acute and chronic SCls were reported ${ }^{12,26-30}$. A recent study reported the use of robotic exoskeleton with two cases with incomplete paraplegia and have found that using HAL may be beneficial for non-ambulatory individuals with acute SCl. ${ }^{26}$ Jansen et al reported improvement in overground walking abilities after 12 weeks of HAL training in individuals with incomplete paraplegia and tetraplegia. ${ }^{27,30} \mathrm{~A}$ case series of eight patients with chronic $\mathrm{SCl}$ showed that a robotic exoskeleton is feasible and safe in application and can lead to improved functional mobility and motor functions in patients with chronic paraplegia or tetraplegia. ${ }^{12} \mathrm{~A} 2017$ study by Grasmücke et al of 55 subjects with incomplete and complete chronic spinal cord injury reported improvement in walking over treadmill and over-ground. ${ }^{28}$ Similarly, Sczesny-Kaiser et al reported improvement in walking parameters and lower limbs muscle power in individuals with chronic traumatic $\mathrm{SCl}$ with incomplete and complete paraplegia after three months of training. ${ }^{29}$ Furthermore, a recent meta-analysis aimed to investigate the benefits of robot-assisted training on the recovery of patients with $\mathrm{SCl}$ suggested that robot-assisted training had better improvement compared with other types of gait training and physiotherapy treatments. ${ }^{14}$

\section{Hybrid Assistive Limb (HAL)}

The Hybrid Assistive Limb (HAL; Cyberdyne, Inc., Japan) is a powered robotic suit with bilateral actuators on the hip and knee joints (that generate torque to move the joints) that attach to the individual's lower limbs. Electromyography electrodes collect surface bioelectrical signals from the flexors and extensors muscles of the hips and the knees. ${ }^{12}$ The level and timing of assistance provided by the machine are adjusted gradually according to the remaining muscle function. This results in synchronization between the individual's bilateral hip and knee movement and the support provided by the exoskeleton. Such variations in gait pattern, stride length, and step height give the opportunity to practice different daily life tasks such as walking over obstacles. ${ }^{12,30,35}$ 


\section{Objectives}

Gait training with powered robotic suits is a new technology in rehabilitation facilities in Saudi Arabia, therefore, this study aims to report whether intensive body weight-supported treadmill training with robotic exoskeleton could improve over-ground functional mobility in individuals with chronic spinal cord injury and to investigate its feasibility and safety.

\section{METHODS}

This study is a case series of two male individuals with chronic (> 1 year since injury) spinal cord injury (SCl). The study was approved by the Institutional Review Board (IRB) at King Fahad Medical City, Riyadh. Both subjects signed consent forms.

\section{Intervention}

All subjects underwent intensive gait training sessions 5 times per week using exoskeleton for 12 weeks with a total of 60 sessions. The duration of the session was 60 minutes, including the installment of the HAL, gait training, and the removal of the HAL. The training was performed on a treadmill with adjustable speed and a lifter, under the supervision of a physiotherapist.

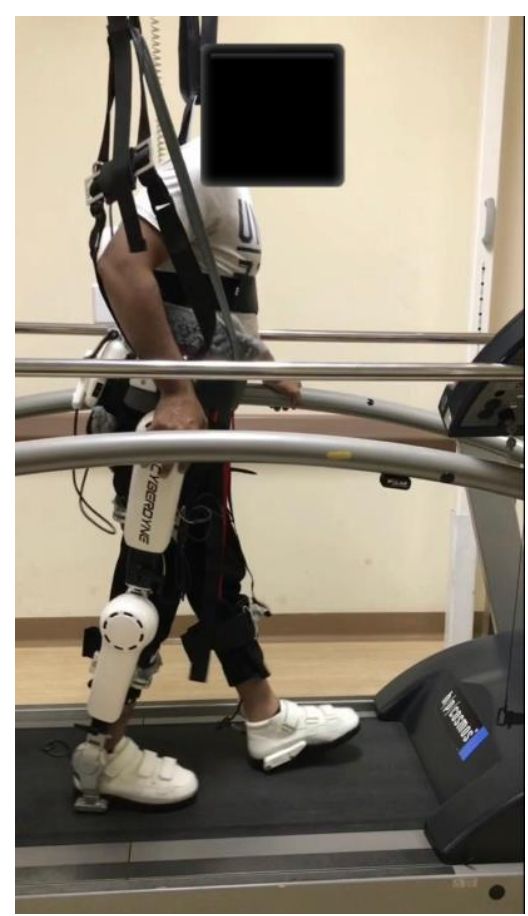

Figure 1. Gait training using a bilateral-leg version of the Hybrid Assistive Limb (HAL)

\section{Outcome Measures}

Two types of outcomes were collected: treadmill-associated data and functional outcomes. The treadmill-associated data, such as walking distance, speed, and time were recorded while using the exoskeleton at every session. On the other hand, functional outcomes were collected while the subjects walked over-ground without the exoskeleton. These were the 10 Meter Walk Test, Timed Up and Go, 6 Minute Walk Test, and Walking Index for SCl. All functional outcomes were measured prior to training (baseline), at 6 weeks, and at 12 weeks (end of training), except for the 6 Minute Walk Test (6 MWT) which was recorded at 6 and 12 weeks only.

The 10 Meter Walk Test (10MWT) is used to measure the time needed (in seconds) to walk a distance of 10 meters at preferred gait speed. Both subjects walked a distance of 14 meters and the time needed to walk the middle 10 meters was measured. ${ }^{36}$ The Timed Up and Go (TUG) is used to measure mobility and balance. It measures the time (in seconds) needed to stand from a chair, walk three meters, turn around, walk back to the chair, and sit down at a comfortable walking speed. The individual is allowed to use an assistive device. ${ }^{37}$ The 6-Minute Walk Test (6MWT) is 
used to measure the distance (in meters) walked by the subjects in 6 minutes. Subjects are instructed to walk at their preferred speed and rest whenever needed. ${ }^{38}$ The Walking Index for $\mathrm{SCl}$ (WISCl-II) is used to measure the amount of physical assistance, braces, or assistive devices required to walk 10 meters. It consists of 20 levels ranging from "unable to stand or walk" (Level 0) to "ambulates 10 meters with no devices, no braces and no assistance" (level 20). ${ }^{39,40}$ The timed measures of ambulation (10MWT, 6MWT, TUG) have excellent test-retest and inter-observer reliability, construct validity, and responsiveness to change in ambulatory individuals with $\mathrm{SCl}$. WISCl-II has moderate to excellent reliability and excellent responsiveness to change. ${ }^{9}$

\section{Case 1: A 27-Year-Old Male}

A 27-year-old male was involved in a road traffic accident that resulted in L1 burst fracture, conus medullaris contusion, and left distal tibia and fibula fractures. He was classified by the International Standards for Neurological Classification of Spinal Cord Injury (ISNCSCI) as ASIA C L1 SCI. He was admitted to a rehabilitation facility immediately after his injury and was hospitalized for 2 months. Three months after being discharged, he was admitted to another rehabilitation facility for 2 months. After that, he received 20 sessions of outpatient physical therapy. At the time of this study, he was not involved in any exercise program in any facility or at home. He is a high school graduate and currently unemployed.

His walking index for SCI (WISCI-II) was 12/20. He walked with two elbow crutches and bilateral ankle-foot-orthosis (AFO) indoors and used a wheelchair for outdoors. His gait pattern showed a flexed trunk and no right knee flexion during the swing phase, he also circumducted his left leg with a kick of the left knee. He moved the elbow crutches simultaneously and used a 3-point gait pattern. He started the intervention 4.3 years post-injury. The characteristics and demographics of both cases are shown in Table 1.

He underwent intensive gait training sessions using the exoskeleton. The training was performed on a treadmill with adjustable speed and a lifter under the supervision of a physiotherapist. The lifter was only used for safety purposes and did not offer any support.

No serious adverse effects were observed during or after the training. The mean walking distance during each session was $433.3 \pm 190$ meters $( \pm \mathrm{SD}$ ). At the end of the training, the following improvements were found in Case 1: TUG from 55.23 seconds to 45 seconds, 10 MWT from 44 seconds to 29 seconds, and 6 MWT from 63.2 meters to 127.8 meters. His gait pattern improved from a 3-point-gait to a 4-point-gait pattern. However, his Walking Index for SCl remained the same; $12 / 20$.

When comparing the treadmill-associated data, we found improvement in treadmill walking speed, distance, and walking time. Table 2 shows the changes in clinical outcome measures between pre and post-HAL treatment of both cases.

\section{Case 2: A 32-Year-Old Male}

A 32-year-old male was involved in a road traffic accident that resulted in an L1-L2 dislocation fracture. He was classified by the International Standards for Neurological Classification of Spinal Cord Injury (ISNCSCI) as ASIA B T12 SCl. After his injury, he received indoor rehabilitation at four different rehabilitation facilities. The average length of stay was 6 weeks in each facility. He denied being involved in any exercise regimen at the time of the intervention. He used to work as a field operator but retired after the injury.

His walking index for SCl (WISCl-II) was 9/20. He walked with a wheeled walker and bilateral Knee-Ankle-Foot Orthosis (KAFO) indoors and used a wheelchair for outdoors. He joined the study 1.8 years post his injury. This individual underwent intensive gait training sessions 5 times per week using the exoskeleton. The training was performed on a treadmill with adjustable speed and a lifter under the supervision of a physiotherapist. The lifter was only used for safety purposes and did not offer any support.

No serious adverse effects were observed during or after the training. The mean walking distance during each session was $313 \pm 134$ ( \pm SD). At 12 weeks, the following improvements were found in Case 2: TUG from 42.46 seconds to 37 seconds, and 6 MWT from 80 meters to 99 meters, but he did not show improvement in 10 MWT and his Walking Index for $\mathrm{SCl}$ remained the same; $9 / 20$. By the end of the training, he started to walk with KAFO on the right lower limb and AFO on the left lower limb with a wheeled walker. He had good hip and knee flexion on the left side without excessive kicking of the knee at the end of the swing phase. Similar to Case 1, the participant showed improvement in treadmill

(c) The Internet Journal of Allied Health Sciences and Practice, 2021 
walking speed, distance, and walking time. Changes in treadmill-associated data and outcome measures are shown in figures 2-7.

\begin{tabular}{l}
\hline Table 1. Patients demographics and clinical characteristics \\
\begin{tabular}{|lcc|}
\hline Demographics & CASE 1 & CASE 2 \\
\hline Age (years) & 27 year & 32 year \\
Gender & Male & Male \\
Height (cm) & 160 & 170 \\
Weight (kg) & 55 & 63 \\
Onset (years) & 4.3 & 1.8 \\
Lesion location & L1 & L1-L2 \\
ASIA & C L1 SCl & B T12 SCl \\
WISCl-II & $12 / 20$ & $9 / 20$ \\
Assistance required during indoor mobility & Two elbow crutches and & Wheeled walker and bilateral \\
& bilateral AFO & KAFO \\
Assistance required during outdoor mobility & Wheelchair & Wheelchair \\
\hline ASIA, American Spinal Injury Association & & \\
WISCI, Walking Index for Spinal Cord Injury. & & \\
AFO, Ankle-Foot-Orthosis & & \\
KAFO, Knee-Ankle-Foot Orthosis & & \\
\hline
\end{tabular}
\end{tabular}

Table 2. Comparison of outcome measures between pre- and post-HAL treatment

\begin{tabular}{|c|c|c|c|c|c|c|}
\hline & \multicolumn{3}{|c|}{ CASE 1} & \multicolumn{3}{|c|}{ CASE 2} \\
\hline & Pre & 6 weeks & 12 weeks & Pre & 6 weeks* & 12 weeks* \\
\hline TUG (seconds) & 55.23 & 69.47 & 45 & 42.46 & 43.8 & 37 \\
\hline 10 MWT (seconds) & 44 & 50 & 29 & 26 & 34 & 30 \\
\hline $6 \mathrm{MWT}$ (meters) & & 63.2 & 127.8 & & 80 & 99 \\
\hline WISCI-II & 12 & 12 & 12 & 9 & 9 & 9 \\
\hline $\begin{array}{l}\text { Treadmill Walking distance } \\
\text { (meters) }\end{array}$ & 56.75 & 602.3 & 693 & 70 & 328 & 348.7 \\
\hline $\begin{array}{l}\text { Treadmill Walking time } \\
\text { (minutes) }\end{array}$ & 11.36 & 30 & 30 & 11 & 14.3 & 17.2 \\
\hline $\begin{array}{l}\text { Treadmill Walking speed } \\
(\mathrm{km} / \mathrm{hr})\end{array}$ & 0.27 & 1.2 & 1.45 & 0.35 & 1.43 & 1.45 \\
\hline
\end{tabular}

TUG, Timed Up and Go

10 MWT, 10 Meter Walk Test

6 MWT, 6 Minute Walk Test

WISCI-II, Walking Index for Spinal Cord Injury

* At 6 and 12 weeks, case 2 started to walk with one AFO and one KAFO compared to bilateral KAFOs pre HAL treatment

\section{Discussion}

The objective of this study was to evaluate the effect of intensive gait training with a robotic exoskeleton on over-ground gait parameters in two individuals with chronic spinal cord injury and to examine its feasibility in clinical settings. The findings from this study provide evidence that HAL can be used in clinical settings with chronic spinal cord injury and may improve walking abilities in terms of distance, speed, and time.

Several recent studies have produced similar encouraging results. Watanabe et al has shown improvement in walking for paraplegic and non-ambulatory individuals during the acute phase after $\mathrm{SCl}$. A pilot study by Aach et al showed that HAL application can result in improved functional mobility and motor functions in patients with chronic paraplegia or tetraplegia. A more recent case series of twenty-one patients with chronic $\mathrm{SCl}$, also found that using $\mathrm{HAL}$ for gait training significantly improved functional mobility and motor functions. ${ }^{30}$ 
Aach et al, Grasmucke et al, Jansen et al, and Sczesny-Kaiser et al all reported significant changes in over-ground walking abilities without using the HAL. 12,27-29 However, in our study, we observed a continuous increase in treadmill walking distance, time, and speed for both cases from baseline assessment until the end of the study at 12 weeks.

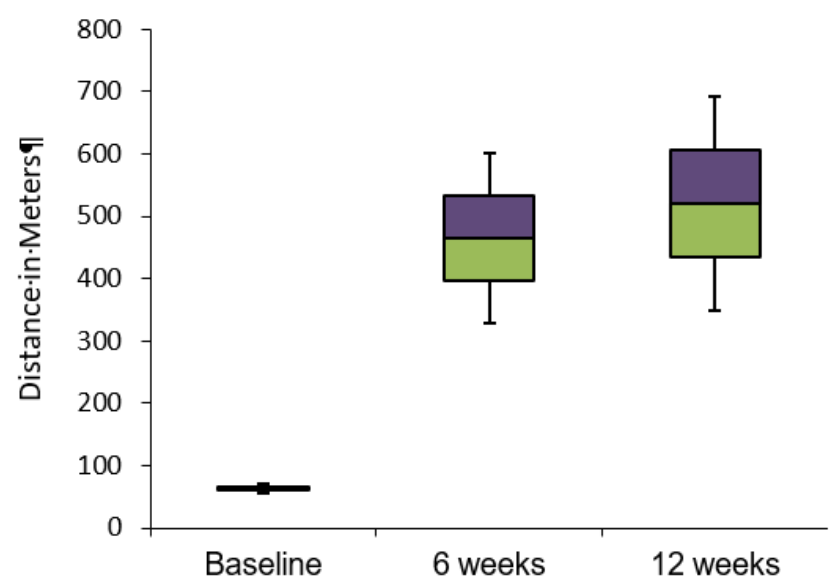

Figure 2. Changes in treadmill walking distance at baseline, 6 weeks, and 12 weeks.

Similar results were detected in the TUG test (Figure 3). There was also an increase in the ambulated distance in 6 MWT. Additionally, case 1 showed improvement in 10 MWT scores, but case 2 did not show improvement in 10 MWT. Moreover, the same subject started the training walking with bilateral KAFOs, but at 6 weeks and onwards he was able to walk with one AFO and one KAFO. This change in the type of orthosis used could have been the reason for the lack of improvement in walking speed (10 MWT).

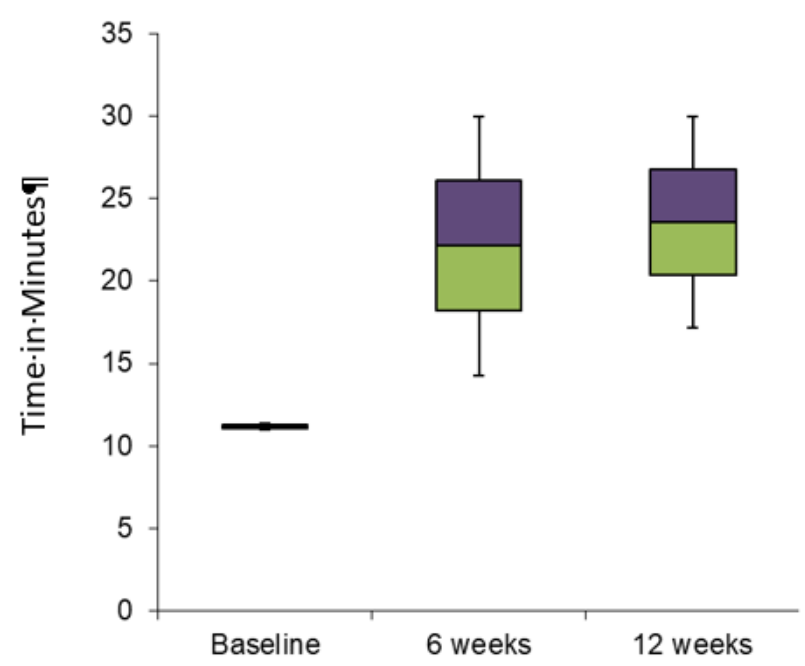

Figure 3. Changes in treadmill walking time at baseline, 6 weeks, and 12 weeks 


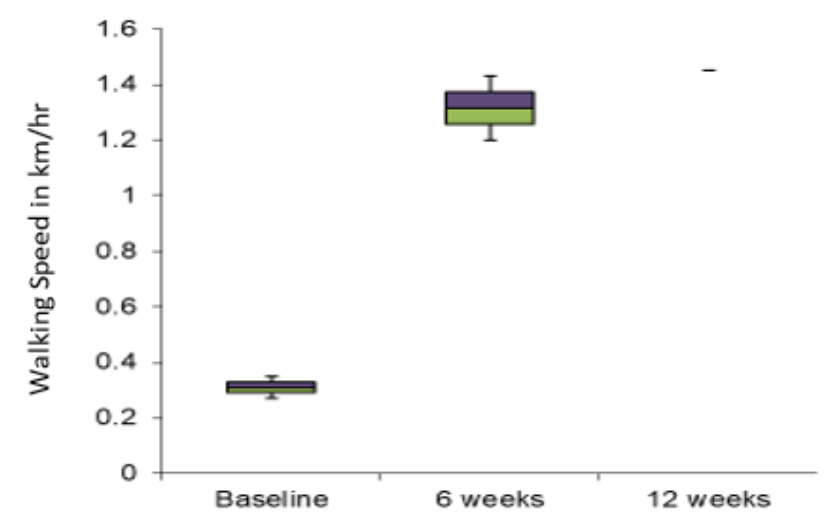

Figure 4. Changes in treadmill walking speed at baseline, 6 weeks, and 12 weeks

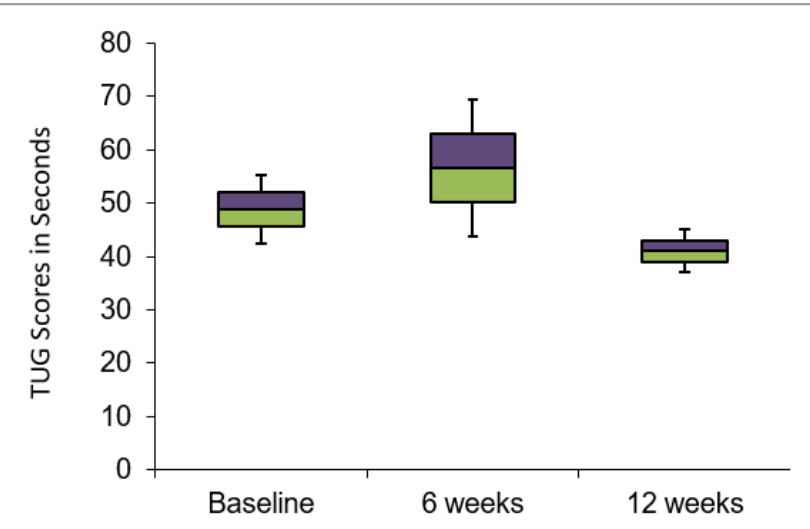

Figure 5. Changes in TUG at baseline, 6 weeks, and 12 weeks

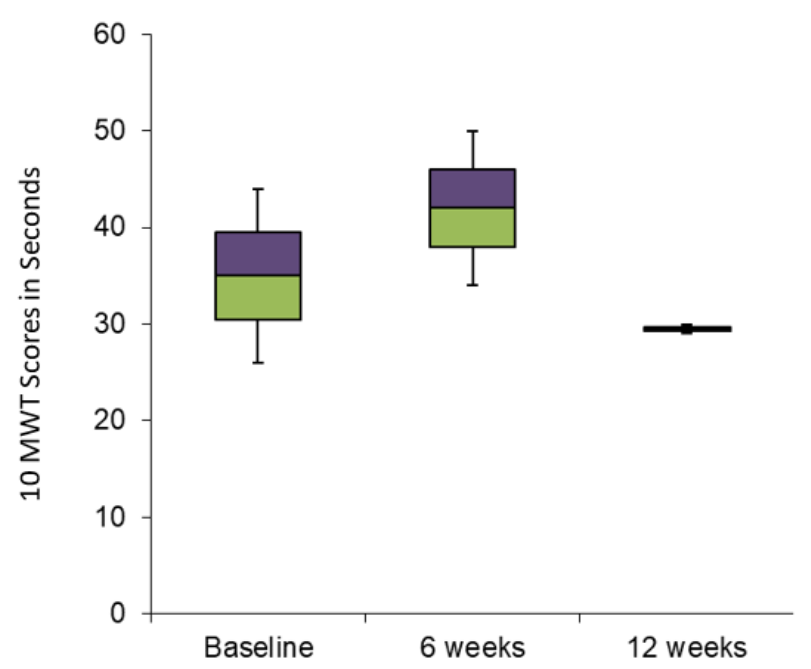

Figure 6. Changes in 10 MWT at baseline, 6 weeks, and 12 weeks 


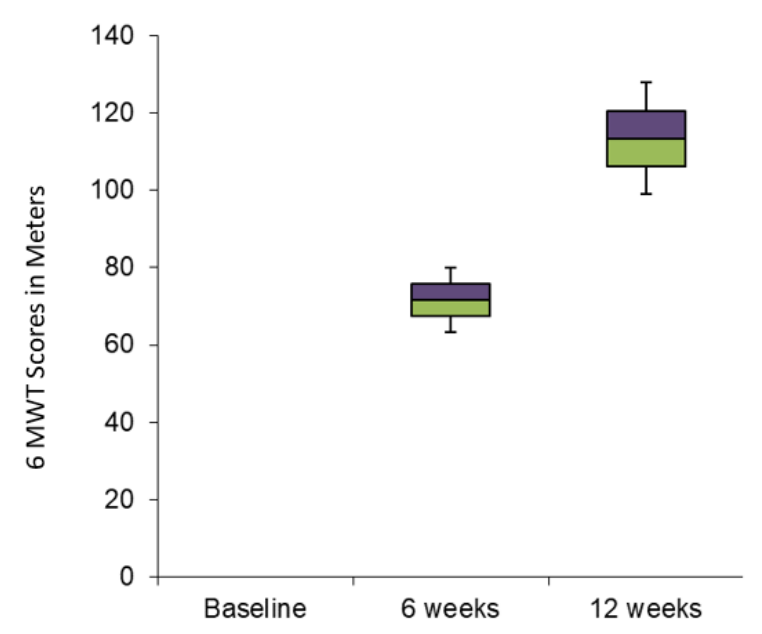

Figure 7. Changes in 6 MWT at baseline, 6 weeks, and 12 weeks

An interesting finding from our case series is that both subjects didn't show any improvement in WISCI-II levels, which is inconsistent with the findings of the previous research ${ }^{12,26-28,30 . ~ I n ~ t w o ~ s t u d i e s, ~ J a n s e n ~ e t ~ a l ~ r e p o r t e d ~ a n ~ i n c r e a s e ~ i n ~ t h e ~}$ WISCI-II score from $10 \pm 1.5$ and $10.7 \pm 4.95$ at baseline to $11.3 \pm 1.3$ and11.7 +4.5 after the intervention, Aach et al reported an increase in the WISCI-II score from $10 \pm 4.34$ to $11.12 \pm 3.68$, Grasmucke et al reported a significant improvement from $9.35 \pm 5.12$ at baseline to $11.04 \pm 4.52$ and Watanabe et al reported an increase in WISCI-II from 4 to 13 in case 1 and from 5 to 18 in case 2. ${ }^{12,26-28,30}$ Lack of improvement in WISCl-II in our subjects might be explained by the average number of training sessions in our study. Our subjects attended 43 out of 60 sessions, which was shorter than other studies. For example, Aach et al, Grasmucke et al, and Jansen et al reported the average number of sessions to be $51.75,58.78,51.75$ and 53.2 sessions, respectively $12,27,28,30$. On the other hand, Watanabe reported significantly fewer number of sessions with an average of 7.5 sessions, however, his subjects received conventional physical therapy and occupational therapy in addition to HAL treatment. ${ }^{26}$ Moreover, he had individuals with acute non-traumatic spinal cord injury with an average onset date of 10.5 days.

Using HAL for gait training in individuals with spinal cord injury is safe as reported by several authors. Aach et al, for example, concluded that treadmill training with robotic exoskeleton is safe and feasible for individuals with chronic incomplete paraplegia12. Another study reported that HAL can be used for gait training early after acute spinal cord infarction ${ }^{26}$. In our study, both subjects did not report any serious adverse effects which may suggest that HAL can be used safely in rehabilitation facilities.

\section{Limitations}

This study is limited because it is a report on two cases with chronic spinal cord injury. The effect of HAL on walking abilities in individuals with chronic $\mathrm{SCl}$ should be studied with a large number of individuals.

\section{CONCLUSION}

HAL can be used for gait training in rehabilitation facilities for individuals with chronic spinal cord injury. Our results support the findings of previous studies that show that treatment with HAL may result in improvement in gait parameters. However, more studies with a larger sample size are needed to compare the effect of HAL with conventional physical therapy.

\section{Conflict of interests}

The author(s) declared no potential conflicts of interest with respect to the research, authorship, and/or publication of this article.

\section{Funding}

The author(s) received no financial support for the research, authorship, and/or publication of this article 


\section{REFERENCES}

1. Fang CY, Tsai JL, Li GS, Lien ASY, Chang YJ. Effects of Robot-Assisted Gait Training in Individuals with Spinal Cord Injury: A Meta-analysis. Biomed Res Int. 2020;2020. doi:10.1155/2020/2102785.

2. Huie JR, Morioka K, Haefeli J, Ferguson AR. What Is Being Trained? How Divergent Forms of Plasticity Compete to Shape Locomotor Recovery after Spinal Cord Injury. J Neurotrauma. 2017;34(10):1831-1840. doi:10.1089/neu.2016.4562.

3. Furlan JC, Noonan V, Singh A, Fehlings MG. Assessment of impairment in patients with acute traumatic spinal cord injury: A systematic review of the literature. J Neurotrauma. 2011;28(8):1445-1477. doi:10.1089/neu.2009.1152.

4. Marino RJ, Ditunno Jr JF, Donovan WH, Maynard Jr F. Neurologic Recovery After Traumatic Spinal Cord Injury: Data From the Model Spinal Cord Injury Systems. Arch Phys Med Rehabil. 1999;80(November):13911396. doi:10.1016/s0003-9993(99)90249-6.

5. Burns SP, Golding DG, Rolle WA, Graziani V, Ditunno JF. Recovery of ambulation in motor-incomplete tetraplegia. Arch Phys Med Rehabil. 1997;78(11):1169-1172. doi:10.1016/S0003-9993(97)90326-9.

6. Waters RL, Yakura JS, Adkins RH, Sie I. Recovery following complete paraplegia. Arch Phys Med Rehabil. 1992;73(9):784-789. doi:10.5555/uri:pii:000399939290144L.

7. Ditunno PL, Patrick M, Stineman M, Ditunno JF. Who wants to walk? Preferences for recovery after SCl: A longitudinal and cross-sectional study. Spinal Cord. 2008;46(7):500-506. doi:10.1038/sj.sc.3102172.

8. Massucci M, Brunetti G, Piperno R, Betti L, Franceschini M. Walking with the Advanced Reciprocating Gait Orthosis (ARGO) in thoracic paraplegic patients: Energy expenditure and cardiorespiratory performance. Spinal Cord. 1998;36(4):223-227. doi:10.1038/sj.sc.3100564.

9. Lam T, Noonan VK, Eng JJ. A systematic review of functional ambulation outcome measures in spinal cord injury. Spinal Cord. 2008;46(4):246-254. doi:10.1038/sj.sc.3102134. 
10. Lam T, Eng JJ, Wolfe DL, Hsieh JTC, Whittaker M. A systematic review of the efficacy of gait rehabilitation strategies for spinal cord injury. Top Spinal Cord Inj Rehabil. 2007;13(1):32-57. doi:10.1310/sci1301-32.

11. Shah M, Peterson C, Yilmaz E, Halalmeh DR, Moisi M. Current advancements in the management of spinal cord injury: A comprehensive review of literature. Surg Neurol Int. 2020;11(2):1-7. doi:10.25259/SNI_568_2019.

12. Aach $M$, Cruciger $\mathrm{O}$, Sczesny-Kaiser M, et al. Voluntary driven exoskeleton as a new tool for rehabilitation in chronic spinal cord injury: a pilot study. Spine J. 2014;14(12):2847-2853. doi:10.1016/j.spinee.2014.03.042.

13. Patrizio S, Andreas W, Marco F, Stefan H. Use of the robot assisted gait therapy in rehabilitation of patients with stroke and spinal cord injury. Eur J Phys Rehabil Med. 2012;48(March):111-121.

14. Cheung EYY, Ng TKW, Yu KKK, Kwan RLC, Cheing GLY. Robot-Assisted Training for People With Spinal Cord Injury: A Meta-Analysis. Arch Phys Med Rehabil. 2017;98(11):2320-2331.e12. doi:10.1016/j.apmr.2017.05.015.

15. Puentes S, Kadone $\mathrm{H}$, Watanabe $\mathrm{H}$, et al. Reshaping of bilateral gait coordination in hemiparetic stroke patients after early robotic intervention. Front Neurosci. 2018. doi:10.3389/fnins.2018.00719.

16. Tan $\mathrm{CK}$, Kadone $\mathrm{H}$, Watanabe $\mathrm{H}$, et al. Lateral symmetry of synergies in Lower Limb muscles of acute poststroke patients after robotic intervention. Front Neurosci. 2018. doi:10.3389/fnins.2018.00276.

17. Kawamoto H, Kamibayashi K, Nakata Y, et al. Pilot study of locomotion improvement using hybrid assistive limb in chronic stroke patients. BMC Neurol. 2013. doi:10.1186/1471-2377-13-141.

18. Mizukami M, Yoshikawa K, Kawamoto H, et al. Gait training of subacute stroke patients using a hybrid assistive limb: a pilot study. Disabil Rehabil Assist Technol. 2017. doi:10.3109/17483107.2015.1129455.

19. Watanabe H, Tanaka N, Goto R, Yanagi H. Effects of Gait Training with a Hybrid Assistive Limb® in Stroke Patients: A Randomized Controlled Study with a 2-month Follow-up. Arch Phys Med Rehabil. 2016. doi:10.1016/j.apmr.2016.08.300.

20. Yoshimoto T, Shimizu I, Hiroi Y, Kawaki M, Sato D, Nagasawa M. Feasibility and efficacy of high-speed gait training with a voluntary driven exoskeleton robot for gait and balance dysfunction in patients with chronic stroke: Nonrandomized pilot study with concurrent control. Int J Rehabil Res. 2015. doi:10.1097/MRR.0000000000000132.

21. Ogata $\mathrm{T}$, Abe H, Samura K, et al. Hybrid assistive limb (HAL) rehabilitation in patients with acute hemorrhagic stroke. Neurol Med Chir (Tokyo). 2015. doi:10.2176/nmc.0a.2015-0209.

22. Watanabe H, Tanaka N, Inuta T, Saitou H, Yanagi H. Locomotion improvement using a hybrid assistive limb in recovery phase stroke patients: A randomized controlled pilot study. Arch Phys Med Rehabil. 2014. doi:10.1016/j.apmr.2014.07.002.

23. Nilsson A, Vreede KS, Häglund V, Kawamoto H, Sankai Y, Borg J. Gait training early after stroke with a new exoskeleton - The hybrid assistive limb: A study of safety and feasibility. J Neuroeng Rehabil. 2014. doi:10.1186/1743-0003-11-92.

24. Yoshikawa K, Mizukami M, Kawamoto H, et al. Gait training with Hybrid Assistive Limb enhances the gait functions in subacute stroke patients: A pilot study. NeuroRehabilitation. 2017. doi:10.3233/NRE-161393.

25. Fukuda H, Samura K, Hamada O, et al. Effectiveness of acute phase hybrid assistive limb rehabilitation in stroke patients classified by paralysis severity. Neurol Med Chir (Tokyo). 2015. doi:10.2176/nmc.0a.20140431.

26. Watanabe H, Marushima A, Kawamoto H, et al. Intensive Gait Treatment Using a Robot Suit Hybrid Assistive Limb in Acute Spinal Cord Infarction: Report of Two Cases. J Spinal Cord Med. 2019;42(3):395-401. doi:10.1080/10790268.2017.1372059.

27. Jansen O, Schildhauer TA, Meindl RC, et al. Functional Outcome of Neurologic-Controlled HAL-Exoskeletal Neurorehabilitation in Chronic Spinal Cord Injury: A Pilot With One Year Treatment and Variable Treatment Frequency. Glob Spine J. 2017;7(8):735-743. doi:10.1177/2192568217713754.

28. Grasmücke D, Zieriacks A, Jansen O, et al. Against the odds: what to expect in rehabilitation of chronic spinal cord injury with a neurologically controlled Hybrid Assistive Limb exoskeleton. A subgroup analysis of 55 patients according to age and lesion level. Neurosurg Focus. 2017;42(5):E15.

doi:10.3171/2017.2.FOCUS171.

29. Sczesny-Kaiser M, Höffken O, Aach M, et al. HAL® exoskeleton training improves walking parameters and normalizes cortical excitability in primary somatosensory cortex in spinal cord injury patients. J Neuroeng Rehabil. 2015. doi:10.1186/s12984-015-0058-9.

30. Jansen O, Grasmuecke D, Meindl RC, et al. Hybrid Assistive Limb Exoskeleton HAL in the Rehabilitation of Chronic Spinal Cord Injury: Proof of Concept; the Results in 21 Patients. World Neurosurg. 2018;110:e73-e78.

(c) The Internet Journal of Allied Health Sciences and Practice, 2021 
doi:10.1016/j.wneu.2017.10.080.

31. Matsuda M, Iwasaki N, Mataki $\mathrm{Y}$, et al. Robot-assisted training using Hybrid Assistive Limb® for cerebral palsy. Brain Dev. 2018. doi:10.1016/j.braindev.2018.04.004.

32. Mataki $Y$, Kamada H, Mutsuzaki H, et al. Use of Hybrid Assistive Limb (HAL $®$ ) for a postoperative patient with cerebral palsy: A case report. BMC Res Notes. 2018. doi:10.1186/s13104-018-3311-z.

33. Matsuda M, Mataki $Y$, Mutsuzaki $H$, et al. Immediate effects of a single session of robot-assisted gait training using Hybrid Assistive Limb (HAL) for cerebral palsy. J Phys Ther Sci. 2018. doi:10.1589/jpts.30.207.

34. Fukaya T, Mutsuzaki H, Yoshikawa K, Sano A, Mizukami M, Yamazaki M. The Training Effect of Early Intervention with a Hybrid Assistive Limb after Total Knee Arthroplasty. Case Rep Orthop. 2017. doi:10.1155/2017/6912706.

35. Louie DR, Eng JJ, Lam T, Spinal Cord Injury Research Evidence (SCIRE) Research Team. Gait speed using powered robotic exoskeletons after spinal cord injury: a systematic review and correlational study. J Neuroeng Rehabil. 2015;12(1):82. doi:10.1186/s12984-015-0074-9.

36. Van Hedel HJA, Dietz V, Curt A. Assessment of walking speed and distance in subjects with an incomplete spinal cord injury. Neurorehabil Neural Repair. 2007;21(4):295-301. doi:10.1177/1545968306297861.

37. Podsiadlo D, Richardson S. The Timed "Up \& Go": A Test of Basic Functional Mobility for Frail Elderly Persons. J Am Geriatr Soc. 1991;39(2):142-148. doi:10.1111/j.1532-5415.1991.tb01616.x.

38. Van Hedel HJ, Wirz M, Dietz V. Assessing walking ability in subjects with spinal cord injury: Validity and reliability of 3 walking tests. Arch Phys Med Rehabil. 2005;86(2):190-196. doi:10.1016/j.apmr.2004.02.010.

39. Ditunno JF, Ditunno PL, Graziani V, et al. Walking index for spinal cord injury (WISCI): An international multicenter validity and reliability study. Spinal Cord. 2000;38(4):234-243. doi:10.1038/sj.sc.3100993.

40. Ditunno PL, Ditunno JF. Walking index for spinal cord injury (WISCI II): Scale revision (Spinal Cord (2001) 39 (654-656)). Spinal Cord. 2009;47(4):349. doi:10.1038/sc.2008.129. 